\title{
Dysplasia Epiphysealis Hemimelica of the Distal Ulna: A CASE Report AND REVIEW OF THE Literature
}

\author{
T. Vogel ${ }^{1}$, T. Skuban², C. Kirchhoff ${ }^{3}$, A. Baur-Melnyk ${ }^{4}$, S. Siegert ${ }^{5}$, B. Heimkes ${ }^{2}$ \\ ${ }^{1}$ Department of Orthopedic and Trauma Surgery, Ruhr-University, Bochum, Germany \\ ${ }^{2}$ Department of Orthopedics, Ludwig-Maximilians-University, Munich, Germany \\ ${ }^{3}$ Depertment of Sports Orthopedics, Technical University, Munich, Germany \\ ${ }^{4}$ Department of Radiology, Ludwig-Maximilians-University, Munich, Germany \\ ${ }^{5}$ Department of Pathology, Ludwig-Maximilians University, Munich, Germany
}

\begin{abstract}
Dysplasia epiphysealis hemimelica (DEH) or Trevor's Disease is a very rare disease with an estimated incidence of one in 1.000.000. The majority of cases reported affect the lower limb and only 25 case reports of 33 cases with affection of the upper limb have been published. Here we present a case of DEH affecting the distal ulnar epiphysis and the lunate in an eleven-year-old girl, a DEH location described extremely rarely before. We firstly do not only present clinical and radiological findings (plane radiographs, CT, MRI), but also the surgical approach and the histopathological results of $\mathrm{DEH}$ in this uncommon location. Although extremely rare, DEH should be considered also in non-typical locations.
\end{abstract}

\section{INTRODUCTION}

Dysplasia epiphysealis hemimelica (DEH) or Trevor's Disease is an uncommon developmental abnormality in young children, characterized by unilateral eccentric overgrowth of an epiphysis. Although most cases of this rare condition are reported on the lower limb, up to date a total of 25 case reports of 33 cases with affection of the upper limb have been published. Reported here is a case of DEH affecting the distal epiphysis of the ulna. Clinical, radiological (plane radiographs, CT, MRI) and histological signs as well as operative treatment will be discussed.

\section{CASE REPORT}

An eleven-year-old girl was seen in November 2006 in our Department of Pediatric Orthopedics with a painful non-traumatic swelling of the ulnar aspect of the left wrist. Clinical examination revealed a bony tumor on the distal end of the left ulna without any signs of inflammation. Active range of motion was significantly reduced due to pain and passive range of motion was limited to five degrees ulna abduction and 20 degrees dorsal extension. Supination and pronation was limited to five and 10 degrees, respectively. Flexion and radial abduction were within normal ranges. There was no family history of bone dysplasia. Plane radiographs of the left wrist (ap and lateral view) showed a massive enlarged distal ulnar epiphysis, the metaphysis seemed to be unaffected (Fig. 1). Furthermore it showed a dorsal subluxation of the ulna and irregularities of the lunate. The radial epiphysis as well as the other carpometacarpal bones appeared normal. The typical radiological picture, together with our clinical findings, led to the suspicion of $\mathrm{DEH}$, although the appearance on the upper extremity is extremely rare and was never seen before in our facility. Because of the patients pain and the limitations of active as well as passive range of motion surgical intervention was indicated. For pre-operative planning computed tomography (CT) and magnetic resonance imaging (MRI) of the wrist was performed to define the anatomic relations. Computed tomography showed that the lesion was not limited to the distal ulna epiphysis, the lunate showed irregularities, too. The distal radio-ulnar joint was not affected (Fig. 2). MRI revealed complete cartilage covering of the tumor and a joint effusion of the wrist. Furthermore it revealed that the triangular discus was stretched but seemed to be intact. It also confirmed the involvement of the lunate. Neither vessels nor the ulnar nerve was affected (Fig. 3). A partial resection of the dysplasia was then performed using a dorsal approach to reduce tumor mass and to allow dorsal extension and ulnar abduction (Fig. 4). Stabilizing elements like the dorsal radio-ulnar ligament or the ulnar collateral ligament were preserved, although they limited the resection. Intraoperatively, the outgrowth was found to be covered with glistening cartilage similar to that of a normal epiphysis, but the surface was irregular and knotty (Fig. 5). After the resection, passive dorsal extension was $45^{\circ}$ and ulnar abduction was $20^{\circ}$. Passive supination was possible up to $30^{\circ}$ and pronation up to $20^{\circ}$. Microscopy of the preparation revealed a benign osteochondroma $(2.7 \times 1.5 \times 1.0 \mathrm{~cm})$ with multiple foci of enchondral ossification (Fig. 6). At follow-up seven weeks after the resection the patient was very satisfied with the functional and cosmetic result, active motion was painless and the wrist was clinically stable. Passive motion of the wrist was $70^{\circ} / 0^{\circ} / 75^{\circ}$ for extension/flexion and $20^{\circ} / 0^{\circ} / 20^{\circ}$ for ulnar and radial abduction. Supination/pronation was possible $20^{\circ} / 0^{\circ} / 10^{\circ}$. The plane $\mathrm{x}$-rays at follow-up are shown in Figure 7. 


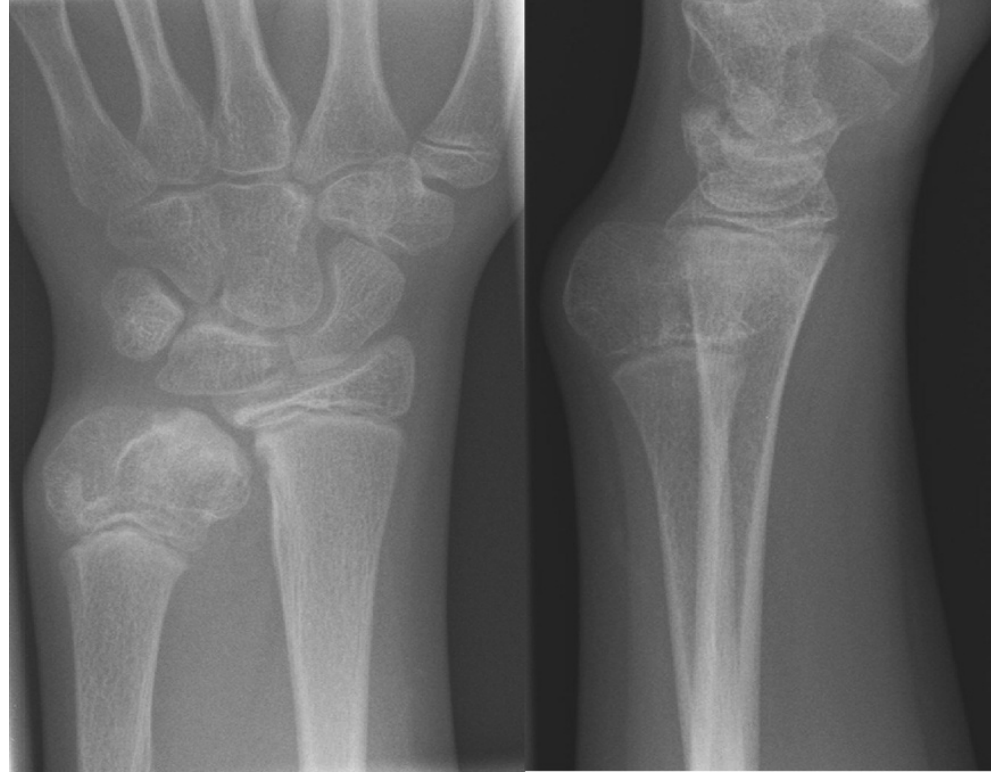

Fig. 1. Tumor limited to the distal ulnar epiphysis, enlarged lunate (plane radiograph ap and lateral view).

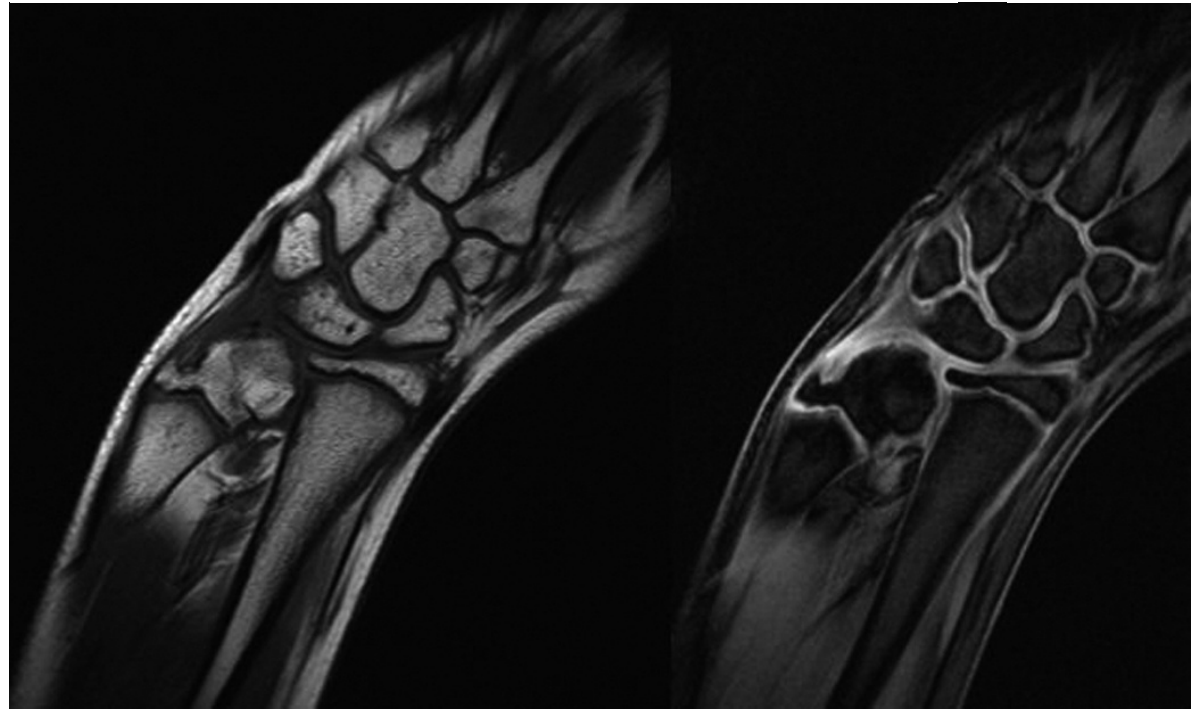

Fig. 3. Ostechondral lesion of the distal ulnar epiphysis, effusion of the wrist, irregularities of the lunate. No bone bruise or osteonecrosis. Stretched but intact triangular discus. No vessel or nerve involvement. (MRI: left T1 wse; right: Flash 3D, cartilage sequence).

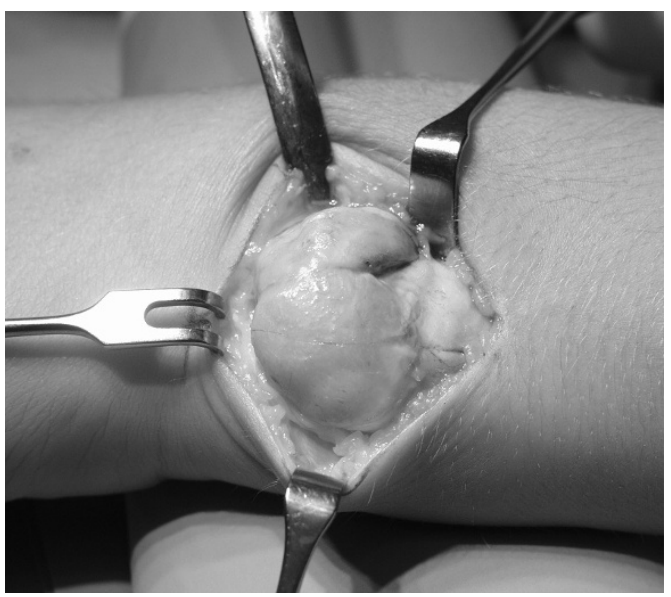

Fig. 4. Intraoperative picture after exposé.

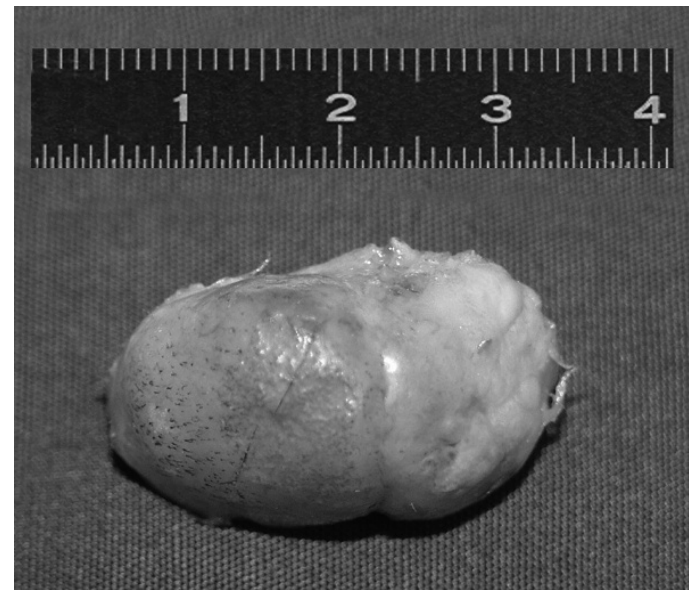

Fig. 5. The mass after resection (scale in $\mathrm{cm}$ ). 

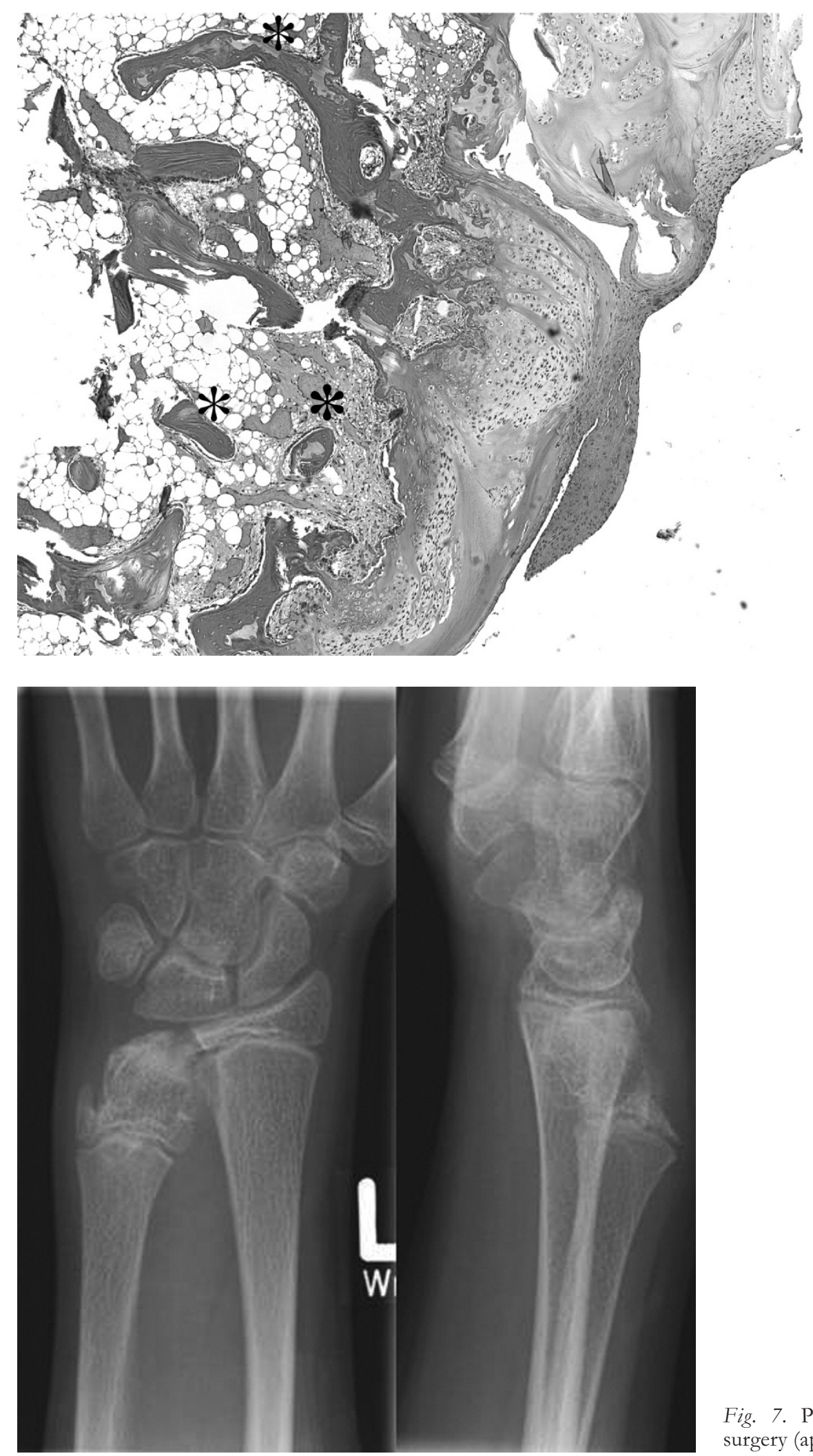

Fig. 6. Histological examination revealed the picture of a benign osteochondroma. The asterix marks multiple centers of bone formation (hematoxylin and eosin; x50).
Fig. 7. Postoperative x-ray seven weeks after surgery (ap and lateral view).

\section{Discussion}

Trevor's disease is an extremely rare condition with an estimated incidence of one in 1.000.000 [10, 11, 37]. The disorder was first described by Mouchet and Belot in 1926 and was called "tarsomegaly" referring to the fact that in the vast majority of the cases the lower limb and especially the foot is affected [25]. Up to now 33 cases (25 case reports) with upper limb involvement are published and DEH of the distal ulnar epiphysis is reported in only 6 cases (Table 1). We performed incomplete resection of the disorder to reduce pain and improve wrist motion in an eleven-year-old girl and present our experience and a review of the lit- 
Table 1. Overview of the current literature of upper limb involvement of dysplasia epiphysealis hemimelica.

\begin{tabular}{|c|c|c|}
\hline Author & No. of Cases & Site \\
\hline Meyerding 1927 (24) & 4 & Carpus \\
\hline Geschickter 1949 (13) & 1 & Scaphoid \\
\hline Fairbank 1956 (9) & 2 & Distal ulna, lunate, scaphoid, trapezium, 1st and 2nd metacarpal \\
\hline Heiple 1961 (14) & 1 & Trapezium \\
\hline Saxton $1964(30)$ & 1 & Proximal humerus, capitellum, radial head, scaphoid, trapezium, 1st metacarpal \\
\hline Wynne-Davies 1973 (37) & 1 & Carpus \\
\hline Hensinger 1978 (15) & 3 & Carpus \\
\hline Buckwalter 1978 (5) & 1 & Distal ulna, lunate \\
\hline Bigliani 1980 (4) & 1 & Glenoid \\
\hline Wiedemann 1981 (36) & 1 & Elbow, carpus \\
\hline Lamesch 1983 (21) & 1 & Radius, scaphoid, trapezium \\
\hline Doyle 1984 (8) & 1 & Scaphoid \\
\hline Cruz-Conde 1984 (7) & 1 & Glenoid, coracoid, humerus, ulna, scaphoid, trapezium, lunate, hamate, capitate \\
\hline Azouz 1984 (2) & 1 & Humerus \\
\hline Stockley 1985 (31) & 1 & Thumb \\
\hline Hoeffel 1986 (17) & 1 & Ulna \\
\hline Maylack 1988 (23) & 1 & Metacarpus \\
\hline Rao 1994 (28) & 1 & Elbow \\
\hline Poli 1995 (27) & 1 & Radius \\
\hline Levi 1998 (22) & 1 & Radius \\
\hline Hoeffel 1998 (16) & 1 & Radius \\
\hline Vanhoenacker 1999 (34) & 1 & Scaphoid \\
\hline Oestreich 2002 (26) & 1 & Radial neck \\
\hline Takeuchi 2003 (32) & 1 & Ulna \\
\hline Beer 2005 (3) & 3 & Carpus \\
\hline Total & 33 & \\
\hline
\end{tabular}

erature. The diagnosis of DEH is mainly radiological and plane $\mathrm{x}$-rays (ap and lateral view) are helpful to recognize the disorder as limited to the epiphysis [7]. There may be generalized though irregular enlargement of the affected epiphysis or a number of separate centers of ossification can be seen. Furthermore, plane radiographs can show weather or not other bony structures are involved [9]. Clinical manifestations consist of pain, swelling, deformities and functional impairment [3, 33, 34]. Males are involved three times as often as females and most patients present between the age of nine month an 14 years [2[. Although there is no definite evidence of familial or hereditary transmission, Hensinger et al. described seven cases in 12 generations of one family $[9,15]$. The etiology remains unknown, although viral involvement has been suggested [29, 35]. Malignant transformation has not been reported [21]. The epiphyseal dysplasias are inborn errors of epiphyseal development and are presumed to be caused by an abnormality of epiphyseal ossification [3]. The natural history of DEH is for the lesion to increase in size until skeletal maturity [20]. Most reported cases have multiple-site involvement in a single lower limb [2]. The most common sites in order are the distal femur, proximal tibia, talus, tarsal navicular and first cuneiform [12]. Our review of the English literature revealed 25 case reports and 33 cases involving the upper extremity (Table 1).

In general, the radial side of the carpus appears to be involved more often [7, 9, 21]. Including our case, only 7 patients with affection of the distal ulnar epiphysis are reported so far. Surgical treatment is indicated when the lesion causes pain, deformity or loss of function. But also cosmetic reasons should be considered. Resection, even if incomplete, has resulted in successful resolution of symptoms in both the lower and upper limbs without risk of recurrence of deformity and a low rate of degenerative changes $[6,9]$. Asymptomatic lesions may be treated nonoperatively [28]. In the patient reported here, pain, functional impairment and cosmetic aspects of the adolescent girl led to surgical treatment. Before the resection a CTscan can help to identify the lesion's anatomic relations and MRI is described to allow better imaging of softtissue lesions, but there have been few reports of MRI in DEH $[1,12,18]$. Like in our case, histologic examination reveals tissue consistent with a benign osteochondroma [19]. The case of a three year old boy reported by Buckwalter in 1977 equals our presented case [5]. Buckwalter performed surgical removal of the mass and the abnormal enlargement did not recur, the surgical procedure itself is not described. At the age of 11 , his patient had equal range of motion of the wrists and no problems with the use of the affected wrist and hand. He described the ossification of the lunate from two centers in his case as "perhaps the most curious feature" in his patient. But other authors like Cruz-Conde, Rao, Buckwalter or Takeuchi found also carpometacarpal involvement in their patients [5, $7,28,32]$. 


\section{Conclusion}

Dysplasia epiphysealis hemimelica is a very rare condition in children and adolescents and is mostly seen in the lower extremity. Affection of the wrist is very rare but there are cases in the literature. In most of those cases the carpal bones are affected. Involvement of the distal ulnar epiphysis is reported in 7 cases including our own case. Surgical resection may be indicated to relieve pain, improve function but also cosmetic reasons have to be considered. When resecting a tumor at the distal radio-ulnar joint stabilizing elements of the distal radio-ulnar joint as well as at the radiocarpal and carpo-ulnar joint have to be preserved.

Recurrence of the lesion seems to be very unlikely independent from the patient's age.

\section{REFERENCES}

1. Abrahams TG, Whitten CG, Jones M, Dorfman HJ. Case report 632. Parosteal osteochondromatous hamartoma associated with Trevor's disease (dysplasia epiphysealis hemimelica). Skeletal Radiol 1991;20(1):47-52.

2. Azouz EM, Slomic AM, Marton D, Rigault P, Finidori G. The variable manifestations of dysplasia epiphysealis hemimelica. Pediatr Radiol 1985;15(1):44-9.

3. Beer TA, Chidgey LK, Wright TW. Dysplasia epiphysealis hemimelica of the carpus. J Surg Orthop Adv 2005;14(1): 42-7.

4. Bigliani LU, Neer CS, Parisien M, Johnston AD. Dysplasia epiphysealis hemimelica of the scapula. A case report. J Bone Joint Surg Am 1980 Mar;62(2):292-4.

5. Buckwalter JA, El-Khoury GY, Flatt AE. Dysplasia epiphysealis hemimelica of the ulna. Clin Orthop Relat Res 1978 Sep;(135):36-8.

6. Connor JM, Horan FT, Beighton P. Dysplasia epiphysialis hemimelica. A clinical and genetic study. J Bone Joint Surg Br 1983 May;65(3):350-4.

7. Cruz-Conde R, Amaya S, Valdivia P, Hernandez M, Calvo M. Dysplasia epiphysealis hemimelica. J Pediatr Orthop 1984 Sep;4(5):625-9.

8. Doyle M, Downey EF. Trevor's disease of the carpal navicular bone: Report of a case. J Am Osteopath Assoc 1984;83:793-4.

9. Fairbank TJ. Dysplasia epiphysialis hemimelica (tarsoephiphysial aclasis). J Bone Joint Surg Br 1956 Feb;38B(1):237-57.

10. Finidori G, Rigault P, Padovani JP, Naouri A. [Hemimelica epiphysialis dysplasia (author's transl)]. Rev Chir Orthop Reparatrice Appar Mot 1978 Jul;64(5):367-74.

11. Fulton H. Dysplasia epiphysialis hemimelica. AMA J Dis Child 1958 Mar;95(3):276-81.

12. Gerscovich EO, Greenspan A. Computed tomography in the diagnosis of dysplasia epiphysealis hemimelica. Can Assoc Radiol J 1989 Dec;40(6):313-5.

13. Geschickter CF, Copeland MM. Tumors of bone. JB Lippincott 1949;37-78.

14. Heiple KG. Carpal osteochondroma. J Bone Joint Surg Am 1961;43A:861-4.

15. Hensinger RN, Cowell HR, Ramsey PL, Leopold RG. Familial dysplasia epiphysealis hemimelica, associated with chondromas and osteochondromas. Report of a kindred with variable presentations. J Bone Joint Surg Am 1974 Oct;56(7):1513-6.

16. Hoeffel C, Hoeffel JC. Dysplasia epiphysealis hemimelica (Trevor's disease) of the distal radius. Acta Orthop Belg 1998 Sep;64(3):343-4.

17. Hoeffel JC, Capron F, Jung JF, Bernard C. Dysplasia epi- physealis hemimelica of the ulna. Eur J Pediatr 1986 Oct; 145(5):450.

18. Keret D, Spatz DK, Caro PA, Mason DE. Dysplasia epiphysealis hemimelica: diagnosis and treatment. J Pediatr Orthop 1992 May;12(3):365-72.

19. Kettelkamp DB, Campbell CJ, Bonfiglio M. Dysplasia epiphysealis hemimelica. A report of fifteen cases and a review of the literature. J Bone Joint Surg Am 1966 Jun;48(4):746-65.

20. Kuo RS, Bellemore MC, Monsell FP, Frawley K, Kozlowski K. Dysplasia epiphysealis hemimelica: clinical features and management. J Pediatr Orthop 1998 Jul;18(4): 543-8.

21. Lamesch AJ. Dysplasia epiphysealis hemimelica of the carpal bones. Report of a case and review of the literature. J Bone Joint Surg Am 1983 Mar;65(3):398-400.

22. Levi N, Ostgaard SE, Lund B. Dysplasia epiphysealis hemimelica (Trevor's disease) of the distal radius. Acta Orthop Belg 1998 Mar;64(1):104-6.

23. Maylack FH, Manske PR, Strecker WB. Dysplasia epiphysealis hemimelica at the metacarpophalangeal joint. J Hand Surg [Am] 1988 Nov;13(6):916-20.

24. Meyerding HW. Exostosis. Radiology 1927;282-8.

25. Mouchet A, Belot J. La tarsomégalie. J Radiol Electrol 1926;10:289-93.

26. Oestreich AE, Mitchell CS, Akeson JW. Both Trevor and Ollier disease limited to one upper extremity. Skeletal Radiol 2002 Apr;31(4):230-4.

27. Poli G, Verni E. Dysplasia epiphysealis hemimelica of the radius. Chir Organi Mov 1995 Jul;80(3):341-4.

28. Rao SB, Roy DR. Dysplasia epiphysealis hemimelica. Upper limb involvement with associated osteochondroma. Clin Orthop Relat Res 1994 Oct;(307):103-9.

29. Rechnagel K. Dysplasia epiphysialis hemimelica. Acta Orthop Scand 1960;29:236-46.

30. Saxton HM, Wilkinson JA. Hemimelical skeletal dysplasia. J Bone Joint Surg Am 1964;46B:608-13.

31. Stockley I, Smith TW. Dysplasia epiphysialis hemimelica an unusual case of macrodactyly of the thumb. J Hand Surg [Br ] 1985 Jun;10(2):249-50.

32. Takeuchi H, Ito K, Ogino T, Hasegawa T, Kitamura M, Ishii S. A case of osteocartilaginous mass involving the coronoid process of the ulna: solitary osteochondroma or dysplasia epiphysealis hemimelica? J Shoulder Elbow Surg 2003 Sep;12(5):510-3.

33. Tovarek J, Fait M. [Dysplasia epiphysealis hemimelica]. Acta Chir Orthop Traumatol Cech 1981;48(6):481-7.

34. Vanhoenacker F, Morlion J, De Schepper AM, Callewaert E. Dysplasia epiphysealis hemimelica of the scaphoid bone. Eur Radiol 1999;9(5):915-7.

35. Wheble VH, Connell MC. Dysplasia epiphysialis hemimelica. Br J Radiol 1958 Nov;31(371):637-9.

36. Wiedemann HR, Mann M, von Kreudenstein PS. Dysplasia epiphysealis hemimelica--Trevor disease. Severe manifestations in a child. Eur J Pediatr 1981 Jul;136(3):311-6.

37. Wynne-Davies R, Hall CM, Apley AG. Atlas of skeletl dysplasias. Churchill-Livingstone, Edinburgh 1985;53943.

Received: June 16, 2008 / Accepted: July 18, 2008

Address for correspondence:

Tobias Vogel, MD

Klinik für Orthopädie und Unfallchirurgie

Klinikum der Ruhr-Universität Bochum

Gudrunstrasse 56

44791 Bochum

Germany

Tel.: +49-234-509-2511

E-mail: t.vogel@klinikum-bochum.de 